\title{
Efficient Optimization Algorithm for Dwindling Payment and Power Management
}

\author{
P. Sangeetha', S. Suja ${ }^{2}$ \\ ${ }^{1}$ Department of Electrical and Electronics Engineering, Faculty of Engineering, Avinashilingam University for \\ Women, Coimbatore, India \\ ${ }^{2}$ Department of Electrical and Electronics Engineering, Coimbatore Institute of Technology, Coimbatore, India \\ Email: sangeethaeeeau@gmail.com, suja@cit.edu.in
}

Received 30 March 2016; accepted 20 April 2016; published 8 July 2016

Copyright (C) 2016 by authors and Scientific Research Publishing Inc.

This work is licensed under the Creative Commons Attribution International License (CC BY).

http://creativecommons.org/licenses/by/4.0/

(c) (i) Open Access

\begin{abstract}
In this current era, rising demand ultimately leads to the scarcity of source in terms of power. To fulfill this inadequacy and because of the availability and easy conversion of electrical energy, hybrid energy system is the best choice for non renewable energy source replacement, which dominates the demand of reliable power. In this paper, we have proposed and analyzed the optimal capacity of the Photovoltaic and Wind as a hybrid system, standing as a foremost motivating force for the public improvement. To provide uninterrupted supply, storage device is used along with the integrated sources. The key pioneering part of this research paper is the performance of the projected system for cost optimization, which is realized by running the Genetic Algorithm (GA) and Particle Swarm Optimization (PSO) algorithms. The result is the baseline system cost necessary to meet the load requirements. The above stated process is implemented using MATLAB. The motivation of choosing these algorithms is because of swift convergence in real time power management. Performance parameter Total Harmonic Distortion (THD) is also calculated for the proposed system.
\end{abstract}

Keywords

GA, PSO, Solar, Wind, EDMS

\section{Introduction}

Power generation and distribution plays a vital role in the power system management. Power generation is done with the help of renewable and non-renewable resources. Usage of non-renewable resources such as coal, petroleum, wood, gas and uranium (radioactive atoms) diminishes because of the need for reuse decays. Moreover in 
the past 25 years, there is a hike in the cost of the fossil fuels. Hence power generation from renewable energy sources poses to be an essential criterion to overcome this problem. Sets of second-life batteries are integrated using converter topology and control architecture for optimal usage in energy storage system [1]. An energy management algorithm (EMA) is proposed for the hybrid energy storage to develop the performance of the battery storage [2]. Exploiting renewable and distributed energy production serves as a substitute for power supply in power markets [3]. Energy transmitting cost between harvester and source is investigated for nominal value [4]. The optimal capacity of the battery storage along with RE source was found thriftily, and the reduced system price was achieved by using the duration cost function at a secure range [5]. Cost comparison of solar, wind sources and batteries acting alone and minimum distance for supplying the customer with conventional power is explained [6]. Combined RE along with fuel cells for supplying the load with the help of control unit and metrics are analyzed to provide qualified and non-interrupting power [7]. The ambiguity of wind energy is proposed to be steadfast by using battery as a storage device reducing the instability of wind energy [8]. Among these resources, wind and solar are most prioritized, thereby initiated and are utilized rapidly in all developed countries with better efficiency [9]. Moreover it regulates the power during power fluctuation and power quality [10] is improved using a dc to dc converter and inverter. Sag, swell and smoothing of voltage and power profiles is concentrated. Fetching of uninterrupted power supply with qualified power is discussed [11]. Ranking of RE sources and optimal sizing of the system is done using algorithms. Sensitivity is calculated [14]. Along with optimal sizing, analysis of reliability of the system requirements is performed and a compromise between cost and reliability is found using epsilon constraint approach [15]. Energy related issues like consumption, operation, expenditure and overhead cost of fossil fuels matters a lot. Research studies and projects have proved that usage of RE (Renewable Energy) such as solar, wind, biomass, hydro power and geo-thermal serves as an alternative for fossil fuel dependency [16]. This hybrid system satisfies the load demand to small grid system, in rural and remote areas. This combination is mainly preferred because PV matches the demand of wind in summer [17] and wind equalizes the demand of PV in winter. Hence to improve power quality and reliability of the system there are several optimization techniques and iterative techniques [18]-[20] that have been suggested by researchers.

The objective of this paper deals with the cost assisted design of a hybrid energy system, to withstand electricity consumption for a small domestic area for varying loads with undisrupted utilization of wind and solar power efficiently. Similar to [5] [8] battery storage is utilized in this work. No fuel cells are used as in [7]. Human beings, living organisms and environment are interactive and interdependent. Genetic algorithm (GA) is human chromosomes based. PSO relies on the swarm intelligence in search of food. Results are obtained using simulation by running Genetic Algorithm (GA) and Particle Swarm Optimization (PSO) algorithms together to obtain the optimized capacity at a reduced cost. Total Harmonic Distortion (THD), a parameter of qualified power, is also obtained. Organization of the paper is as follows: Section 2 deals with related literatures, Section 3 describes the background process, Section 4 explains the proposed method and algorithms, Section 5 with results and finally Section 6 ends up with conclusion.

\section{Correlated Literature Review}

Xin Kang et al. (2014) explained about minimization of energy consumption and total energy cost by considering problem of communicating over a block fading channel in which transmitter has access to an energy harvester and a conventional energy source and this was investigated under upper bound and lower bound using Linear Programming based Channel Removal (LPCR) and Worst Channel Removal (WCR) respectively [4].

W.D. Kellogg et al. (1998) proposed an investigation on hybrid PV/wind for power generation to utilize a stand-alone system in south-central Montana between Broadview and Townsend and discussed about the development for the design of a hybrid wind/PV using a simple iterative algorithm technique [6].

Mohammed Alsayed et al. (2013) has dealt with the optimal sizing of PV/wind using Multi criteria decision analysis (MCDA) by considering different weighing criteria with different fluctuation scenarios of wind speed and solar radiation profiles and thus discussed detail about merits and demerits of the proposed system [14].

Amirsaman et al. (2014) proposed a stochastic optimization method to optimize the hybrid system (wind/PV) to improve the performance and reliability of the system using sequential Monte Carlo simulation technique which generates data in time. The generated sequential samples in numerous intervals improved the performance of the system [15]. 


\section{Background Process}

The background process consists of the following components like description of wind turbine, rectifier, photovoltaic cell, dc to dc converter, battery storage unit and inverter.

\subsection{Wind Turbine Description}

Wind turbine generates electric energy from wind using turbine generator. Wind turbine consists of blade, shaft and generator and it is classified based on wind axes, dimensions and number of blades. With this consideration there are three types of wind turbines which are used to generate electric energy. Initially, three bladed turbines are used and it is placed towards the direction of wind. Secondly two bladed wind turbines are a downwind turbine and finally single blade turbines, which are rarely used. From the above types of turbine, in our simulation process, the three bladed turbines are being considered. Equation (1) represents the calculation of wind turbine power with respect to the wind speed which is represented as,

$$
P_{T}= \begin{cases}0 & \text { for } S_{W} \leq S_{C}, S_{W} \geq S_{F} \\ P_{W T-\text { rated }} *\left[\frac{S_{W}-S_{C}}{S_{R}-S_{C}}\right]^{3} & \text { for } S_{C} \leq S_{W} \leq S_{R} \\ P_{W T \text {-rated }} & \text { for } S_{R} \leq S_{W} \leq S_{F}\end{cases}
$$

\subsection{Rectifier}

Figure 1 shows the three-phase diode bridge rectifier. It has three-phase diode bridge with comprising diodes $\mathrm{S}_{1}$ to $S_{6}$. The load current I is constant. The rectifier is supplied by a balanced uninterrupted three-phase voltage system, specified by the phase voltages. It is represented in Equation (2), Equation (3) and Equation (4) as $V_{1}, V_{2}$, and $V_{3}$ respectively.

There are two bridges that conduct internally with respect to the conducting diode. The first conducting diodes are $\left\{\mathrm{S}_{1}, \mathrm{~S}_{3}\right.$ and $\left.\mathrm{S}_{5}\right\}$; the highest phase voltages are connected to the anodes of each conducting diode. The second conducting diode is from the group of even-indexed diodes $\left\{\mathrm{S}_{2}, \mathrm{~S}_{4}\right.$ and $\left.\mathrm{S}_{6}\right\}$; the lowest phase voltages are connected to cathode. The current $I$ is strictly greater than zero during the whole period.

$$
\begin{gathered}
V_{1}=V_{m} \cos \omega_{0} t \\
V_{2}=V_{m} \cos \left(\omega_{0} t-\frac{2 \pi}{3}\right) \\
V_{3}=V_{m} \cos \left(\omega_{0} t-\frac{4 \pi}{3}\right) \\
V_{m}=V_{r m s} * \sqrt{2}
\end{gathered}
$$

Since one phase voltage cannot be the highest and the lowest at the same time for the given set of phase voltages specified by Equation (2), Equation (3) and Equation (4), two of the phases are connected to the load while

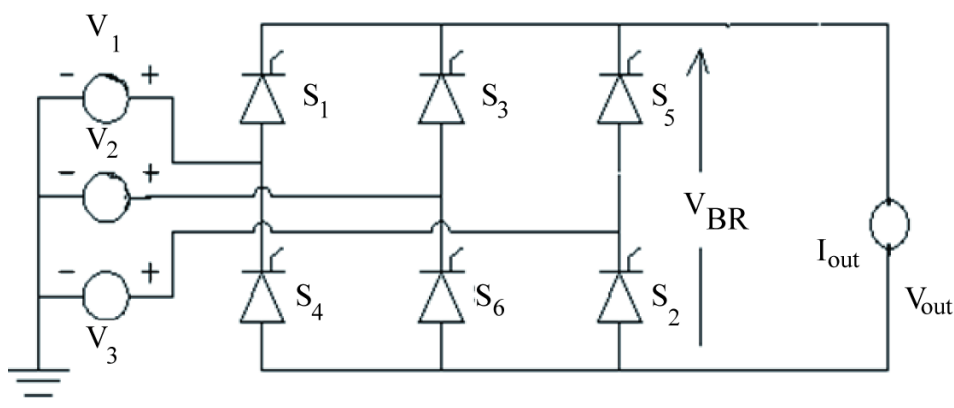

Figure 1. Three phase diode bridge rectifier. 
one phase is disconnected every time. This results in an input current equal to zero in the time interval when the phase voltage is neither maximal nor minimal. The operation of the diode bridge output terminal voltage is equal to the maximum of the phase voltages, represented in Equation (5).

\subsection{Photovoltaic Cell, Converter, Storage Unit and Inverter}

Several groups of cells form a solar PV module and several modules form a photovoltaic array [12] [13]. Modules are connected by the wire, either in series or parallel to increase the voltage or current respectively. Equation (6) represents the output power of PV array calculated with respect to solar radiation.

$$
P_{P V}=\left(\frac{R_{P E R P}}{1000} * P_{P V-\text { rated }} * \eta_{M P P T}\right)
$$

where $R_{P E R P}$-Perpendicular radiation at array's surface $\left(\mathrm{W} / \mathrm{m}^{2}\right)$

$P_{P V \text {-rated }}$ - Rated power of each PV array at $R_{P E R P}=1000 \mathrm{~W} / \mathrm{m}^{2}$

$\eta_{M P P T}$-Efficiency of MPPT system

The required voltage is obtained by using the boost converter which produces the output voltage equal to or greater than input voltage. If the output voltage is increased then available output current must decrease. MOSFETs are used in power switching, the choice being determined by the voltage, current, switching speed and cost considerations. The battery stores the excessive power generated by the wind turbine and the PV array that powers the load (battery charging state). The battery discharges when the power generated by the wind turbine and the PV array is lesser than the power drawn by the load (battery discharging state). Equation (7) and Equation (8) represents the charging and discharging power of the batteries.

$$
\begin{gathered}
P_{\text {BATT }}(t)=P_{\text {BATT }}(t-1) *(1-S D)+\left[P_{\text {TOT }}(t)-\frac{P_{L O A D}(t)}{\eta_{I N V}}\right] * \eta_{B-\text { Charging }} \\
P_{\text {BATT }}(t)=P_{\text {BATT }}(t-1) *(1-S D)+\left[\frac{P_{L O A D}(t)}{\eta_{I N V}}-P_{T O T}(t)\right] * \eta_{B-\text { Discharging }}
\end{gathered}
$$

where $P_{\text {BATT }}(t)$-Battery charged at the time of $t$

$P_{\text {BATT }}(t-1)$ - Battery charged at the time of $(t-1)$

$(1-S D)$ - Self discharge rate of battery per hour

$P_{\text {TOT }}(t)$-Total power generated from turbine and PV array in the time interval $(t-1, t)$

$P_{L O A D}(t)$ - Total power by load in the time interval $(t-1, t)$

$\eta_{I N V}$-Efficiency of an inverter

$\eta_{B-\text { Charging }}$ Efficiency of a battery at charging time

$\eta_{B-\text { Discharging }}$ Efficiency of a battery at discharging time

Energy stored in the battery is taken by electrical loads through the inverter, which converts DC power into AC power. The inverter has in-built preservation for short-circuit; reverse polarity, low battery voltage and over load.

\section{Proposed Methodology}

\subsection{Block Diagram of Hybrid Energy System for Proposed Methodology}

The proposed method is illustrated in Figure 2 which is designed with the wind turbine, PV array, battery storage unit, boost converter, inverter and loads. The hybrid energy system can be divided into three main stages. The first stage is generation side which includes PV, wind and battery systems. The second stage is the conversion and storage systems. The conversion system includes the AC to DC converter for the wind generators, the DC to DC converters for the PV systems and DC to AC inverters which are connected to the DC bus. The third stage represents the power supply to AC or DC load for house hold appliances. Figure 2 shows the block diagram of proposed methodology optimization technique of the PV-wind hybrid system. Energy demand management system (EDMS) at a reduced cost is used to compensate the energy for varying loads with the help of optimally cost effective GA and PSO algorithms. 


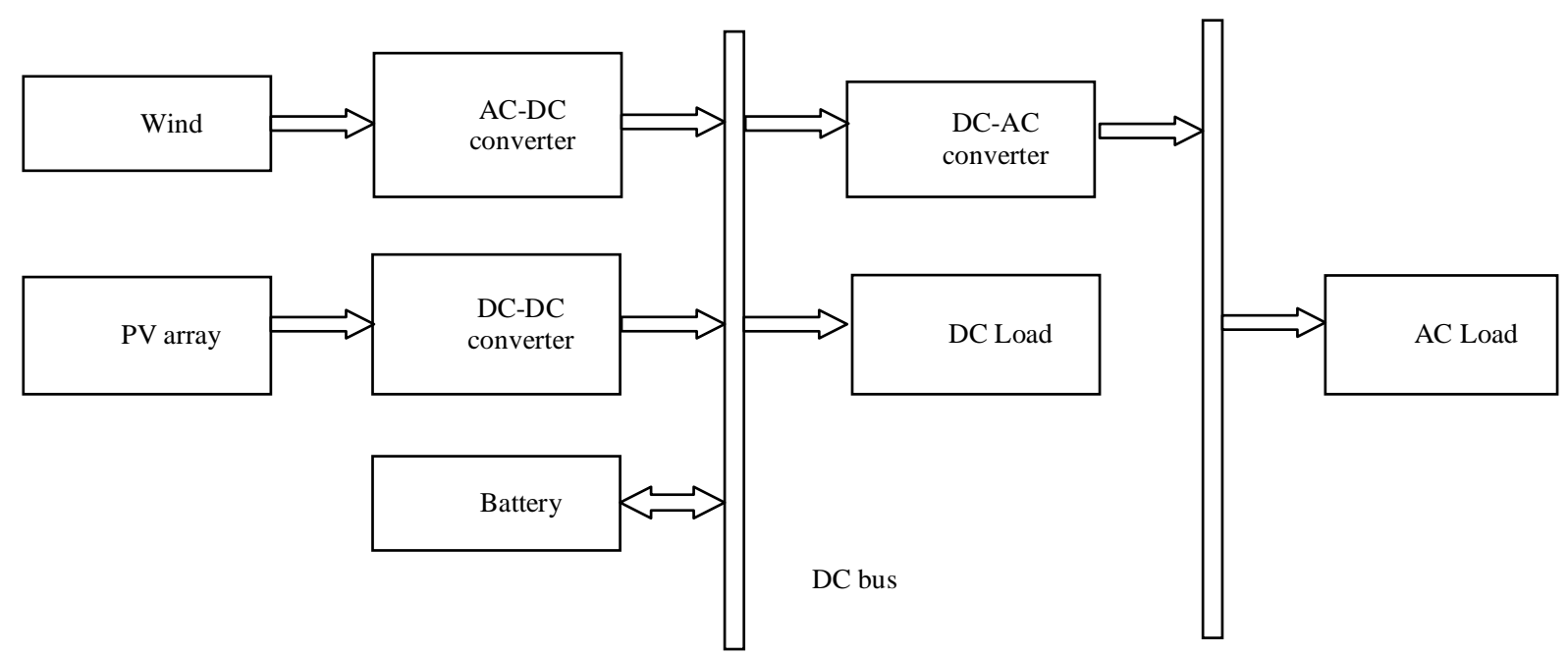

Figure 2. Block diagram of hybrid energy system.

\subsection{Hybrid Energy System}

Hybrid Renewable Energy Systems (HRES) is the most economical and sustainable in electrification as per the cited papers [1]-[3] [17]. Hence the two energy sources provide continuous energy production to supply the demand. Figure 3 and Figure 4 represents the pseudo code and flowchart of the algorithms. Equation (9) depicts the system cost calculation. Equation (10) indicates the real interest rate calculation formula.

$$
\begin{gathered}
C=N_{u} *\left(C_{\text {cost }}+R_{\text {cost }} * k+M_{\text {cost }} * \frac{1}{\operatorname{CRF}\left(r_{i}, L\right)}\right) \\
r_{i}=\left(\frac{r_{i-n o m i n a l}-a_{\text {ir }}}{1+a_{\text {ir }}}\right)
\end{gathered}
$$

where, $N_{u}$ is the number of units

$L$ is the useful lifetime of the project

$r_{i}$ is the real interest rate which is a function of $r_{i-n o m i n a l}$ and annual inflation rate

CRF is the capital recovery factor and obtained as shown in Equation (11).

$k$ is the single payment present worth as shown in Equation (12).

$$
\begin{gathered}
\operatorname{CRF}\left(r_{i}, L\right)=\frac{r_{i} *\left(1+r_{i}\right)^{L}}{\left(1+r_{i}\right)^{L}-1} \\
k_{i}\left(r_{i}, L T_{i}, r C_{i}\right)=\sum_{n=1}^{r c_{i}} \frac{1}{\left(1+r_{i}\right)^{n * L T_{i}}}
\end{gathered}
$$

$r c_{i}=\left[\frac{1}{L T_{i}}\right]-1$; if $L$ and $L T_{i}$ are divisible

$r c_{i}=\left[\frac{1}{L T_{i}}\right]$; if $L$ and $L T_{i}$ are not divisible

where, $L T_{i}$-Useful lifetime of the project

$r c_{i}$-Number of replacements of the component during the lifetime of the project.

Hence the objective function is represented in Equation (13) as,

$$
\text { System cost }=\text { System cost } t_{W T}+\text { System } \operatorname{cost}_{P V}+\text { System cost }_{B A T T}+\text { System cost }_{I N V}
$$


Pseudo Code for Cost Optimization using GA AND

PARTICLE SWARM OPTIMIZATION (PSO)

begin

Input weather data and component cost

Initialize the GA and PSO parameters

Randomly generated initial populations

Calculate the fitness value

Obtain the next generation by updating rotation and speed

Update the pbest and gbest in each iteration

end

Global best individual in the population

Figure 3. Pseudocode for cost optimization.

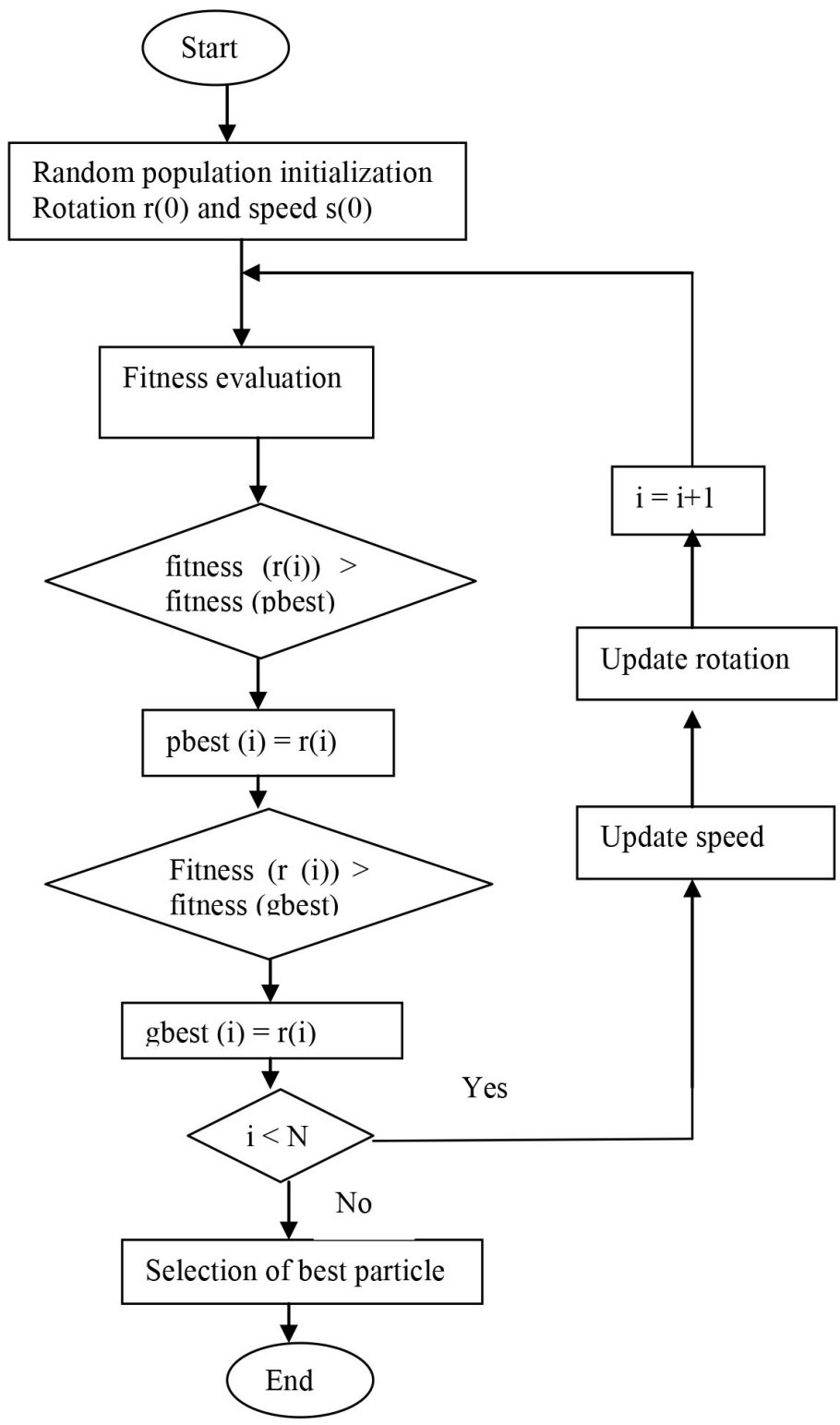

Figure 4. Flowchart for the GA/PSO algorithm. 
Equation (16-18) represents the constraints of the proposed system collectively.

The constraint for the total demand supplied by the hybrid system is represented as

$$
P_{W T}+P_{P V}+P_{\text {BATT }} \geq P_{\text {Load }}
$$

The constraints of the number of PV array, battery and wind turbine is represented as

$$
N_{P V}, N_{W T}, N_{B A T T} \geq 0
$$

The constraint for the battery capacity is represented as

$$
P B_{\min } \geq P B \geq P B_{\max }
$$

where $P B_{\min }$-minimum battery capacity

$P B$ - rated battery capacity

$P B_{\max }$ —maximum battery capacity

$$
P B_{\text {min }}=(1-D D) * P B_{\text {max }}
$$

where, DD is the depth of discharging

\subsection{Genetic Algorithm and Particle Swarm Optimization}

Genetic Algorithm is a method of optimization based on human chromosomes and gene combination and functions. This method, with five types of parts undergoes much iteration for the fed data input and the optimized size. GA proves good for numeral based optimization solutions. Particle swarm optimization, well suited for continuous design problem solving, is a population-based stochastic optimization technique. PSO algorithm hires the priority in population of particles. Inputs as three parameters are used to update the velocity equation. The first is the momentum component, remembering controls about the previous speed of the particle. The second component is the cognitive component, controlling the particle head towards its personal best rotation. The third component, referred to as the social component, draws the best rotation of particle swarm. The acceleration constant controls this tendency. The state of each particle is represented by rotation and speed represented in Equation (18) and Equation (19).

$$
\begin{gathered}
P_{i}=\left(r_{i 1}+r_{i 2}+\cdots+r_{i n}\right) \\
s_{i}=\left(s_{i 1}+s_{i 2}+\cdots+s_{i n}\right)
\end{gathered}
$$

The state of particles is updated. The two best values are updated in each particle as the first rotation of the best fitness value. The fitness value is given in Equation (20).

$$
P_{i}=\left(P_{i 1}+P_{i 2}+\cdots+P_{i n}\right)
$$

This value is stored as the p best, another "best" rotation is tracked by the particle swarm as the current global best and is given in Equation (21). Equation (22) and Equation (23) represents the speed and rotation formulae.

$$
\begin{gathered}
P_{g}=\left(P_{g 1}+P_{g 2}+\cdots+P_{g n}\right) \\
S_{i}^{k+1}=W S_{i}^{K}+C_{1} L_{1}\left(p_{b e s t}-r_{i}^{k}\right)+C_{2} L_{2}\left(g_{\text {best }}-r_{i}^{k}\right) \\
r_{i}^{k+1}=r_{i}^{k}+S_{i}^{k+1}
\end{gathered}
$$

where $W$-Inertial constant

$K$-Capital recovery factor

$L$-Useful lifetime of the project

$C_{1}, C_{2}$-acceleration constant

$S_{i}$ - Speed, $r_{i}$-Rotation

The constraints of the of the number of PV array, battery and wind turbine system as indicated in Equation 16 and restraint for the battery capacity as indicated in Equation 17 are considered. The Equation (24) shows the main constraint to be satisfied.

$$
P_{1} * N_{1}+P_{2} * N_{2}=L
$$


where $P_{1}$-Photovoltaic power from PV source

$N_{1}$ - Number of PV panels

$P_{2}$-Produced power from Wind Turbines

$\mathrm{N}_{2}$ - Number of Wind Turbines

$L$-Electric load demand

The input of the system is weather data and system components that initialize the parameters for the fitness calculation. The rotation and speed are updated for the next generation and the values $\mathrm{p}$ best and $\mathrm{g}$ best are obtained for all iterations, and the global best value for the given population is also fetched. The GA and PSO algorithms are performed to determine the optimum balance of the system to meet the energy demand. Wind speed data, solar irradiation data, demand data, and the battery SOC (State of Charge) are the input values to the optimal block. The proposed optimization system operates in real-time, and so fast and accurate optimization methods are taken on. If any changes in the input data occur during the optimal intervals, the storage battery will respond to the power transients. Figure 4 shows the procedure for GA and PSO algorithm in hybrid system for cost optimization. Rotation and speed are initialized randomly, the number of iterations is 1300 and number of population is 150 . The fitness value is calculated by GA and then by PSO, updating rotation and speed in each particle. If best value is less than the number of iterations the above procedure is repeated, and if not satisfied the global best value is selected, and it is called global best value (gbest).

\section{Experimental Results}

This paper focuses on the eco friendly solar and wind sources. On inclusion of the solar source in the circuit, based on historical data, solar generated voltage is fetched as 500 volts, current value as 50 amps and the DC solar power is equal to $2.5 \times 10^{4}$ with respect to 0.05 seconds for hybrid energy systems. The solar power $2.5 \times$ $10^{4}$ watts, maintains the same voltage with respect to time. This magnitude maintenance is essential for stability criterion, focusing for improved load demand management. Mat lab based Figure 5 shows the magnitude of the solar voltage, solar current and solar power waveforms with respect to time.

In addition to PV arrays, wind source is now included. Using three bladed turbines, with respect to the wind speed and based on Equation (1), wind power is obtained. Using historical data feed, Figure 6 shows the wind voltage, wind current, real power and reactive power waveforms with respect to time. The three phase diode bridge rectifier is used to balance the three-phase voltage of the system. The real and reactive power has harmonics in power generation at the starting time. The real power value is $2.5 \times 10^{4}$ watts and reactive power of wind turbine is $1 \times 10^{4}$ watts with respect to time of $0.1 \mathrm{~s}$. Figure 7 shows the boost output voltage. The MOSFET

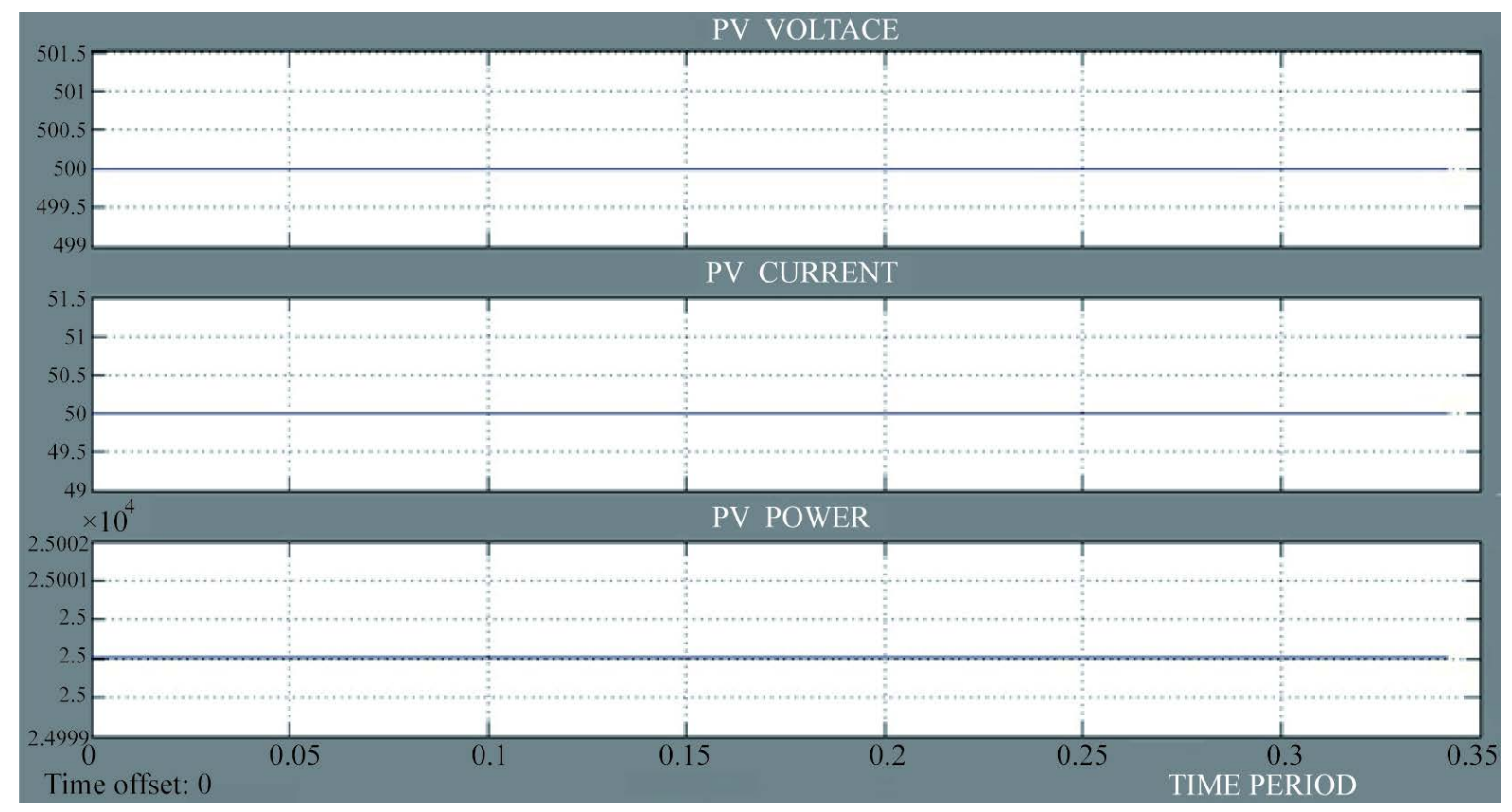

Figure 5. Solar voltage, current and power. 


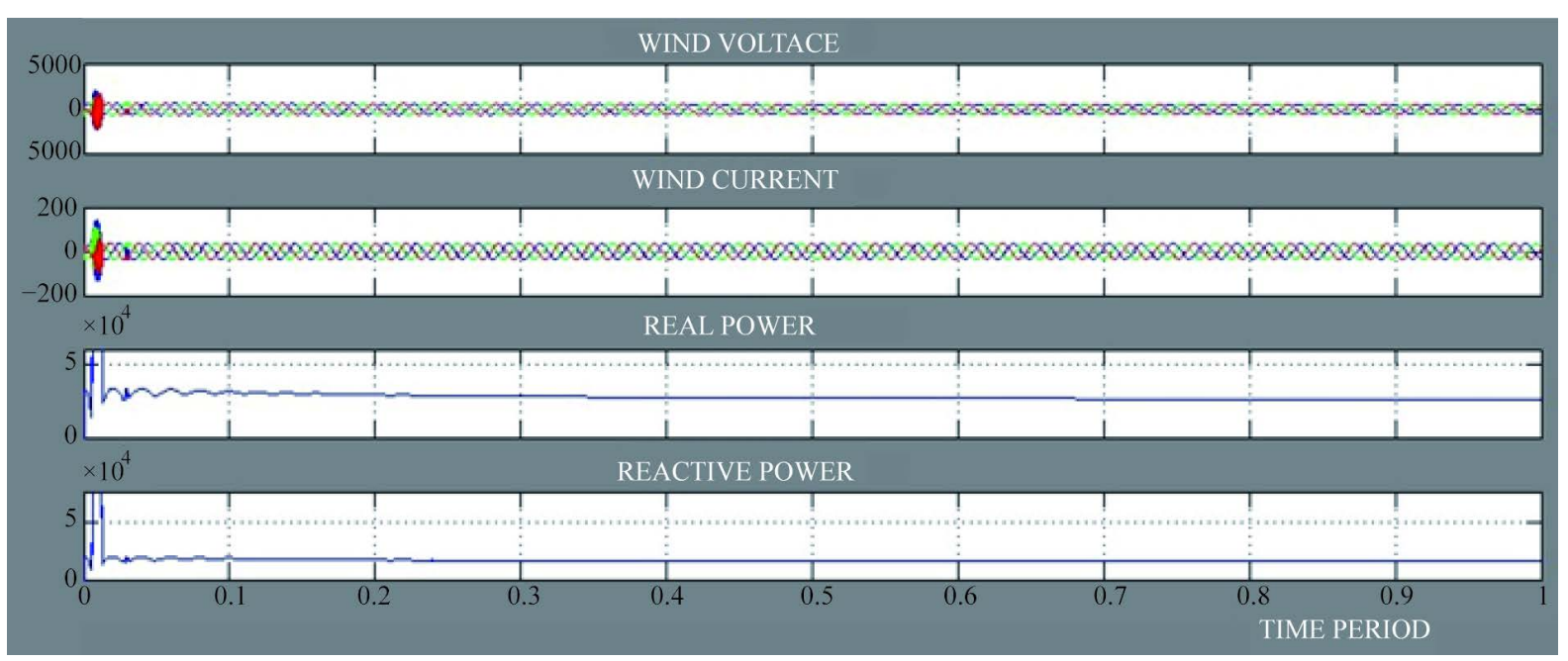

Figure 6. Wind voltage, current, real power and reactive power.

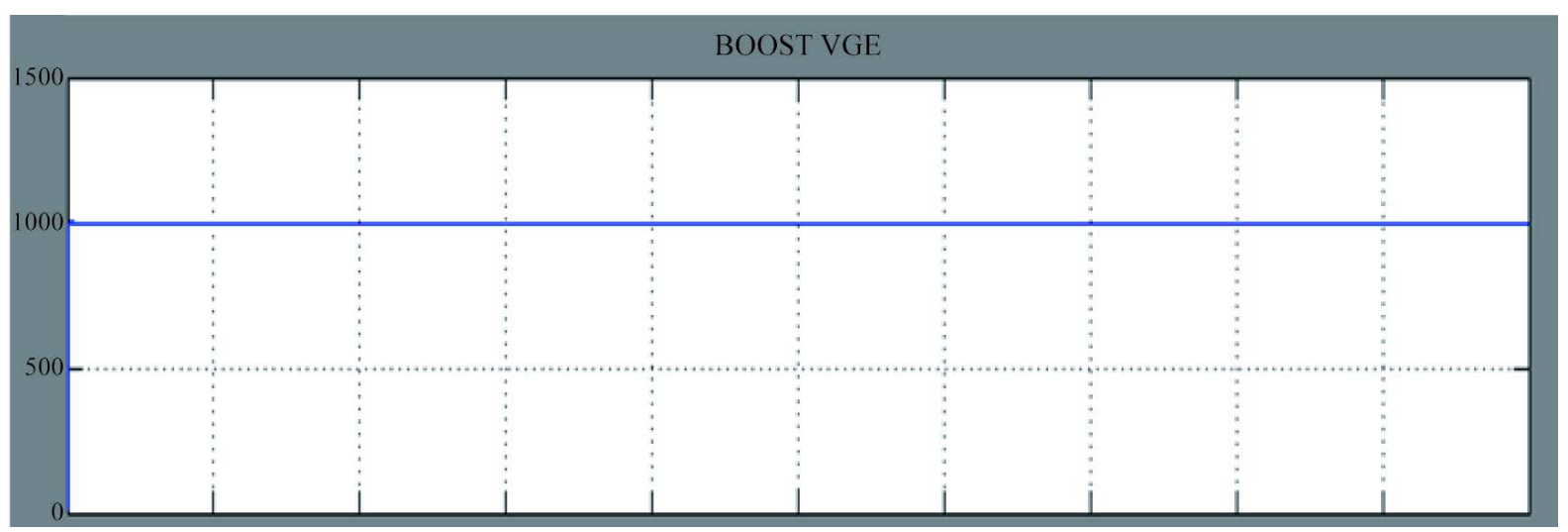

Figure 7. Boost voltage.

based boost converter is used to increase the output voltage to 1000 volts and the boosted value is now greater than the input voltage. Based on the power management, excess electrical energy can be saved by charging a battery, which power can also be discharged when in demand for load adjustment. Figure 8 shows the battery voltage capacity as 1000 volts for the hybrid energy system. The three systems such as solar, wind and battery are connected to the DC bus and on the flip side of the DC bus, DC load is connected. Figure 9 shows the DC bus voltage, current and power with respect to time. The magnitude of the DC bus voltage is 1000 volts, current is 50 amps and power is $5 \times 10^{4}$ watts with respect to time. Based on the flip side connection, Figure 10 shows the load voltage, current and power with respect to time.

The 3phase voltage, current, real and reactive powers are calculated. The load side of real and reactive power has harmonics in the starting period. The real power is $5 \times 10^{4}$ watts and reactive power is $3 \times 10^{4}$ watts with respect to time and this maintains the stability of the power with respect to time. To meet the AC load requirements, the inverter is used for converting the DC voltage into AC voltage. Table 1 defines the input parameters used for the work. Finally the GA and PSO algorithms are run to obtain the optimum installation cost as 4.7570 and total harmonic distortion (THD) value is obtained as $0.54 \%$ for 1300 numbers of iterations and 150 number of population.

\section{Conclusion}

This manuscript examines the efficiency of a hybrid system that combines renewable energy generation and energy storage to meet a controllable load. A smart-grid approach is urbanized to alter the load and counterpart the renewable power generation and load. This method is modeled in MATLAB with PV array, wind and battery. 


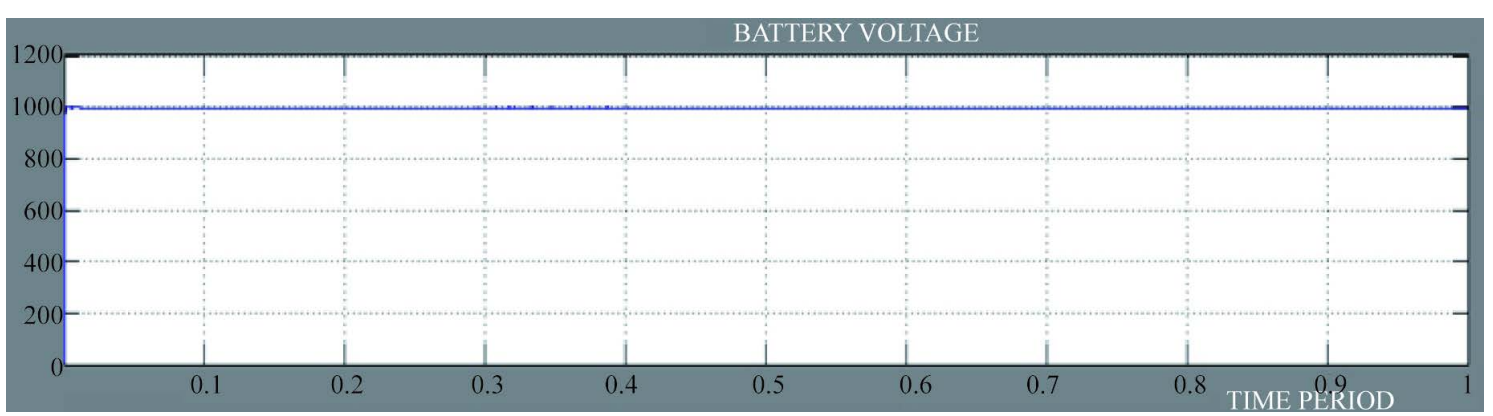

Figure 8. Battery voltage.

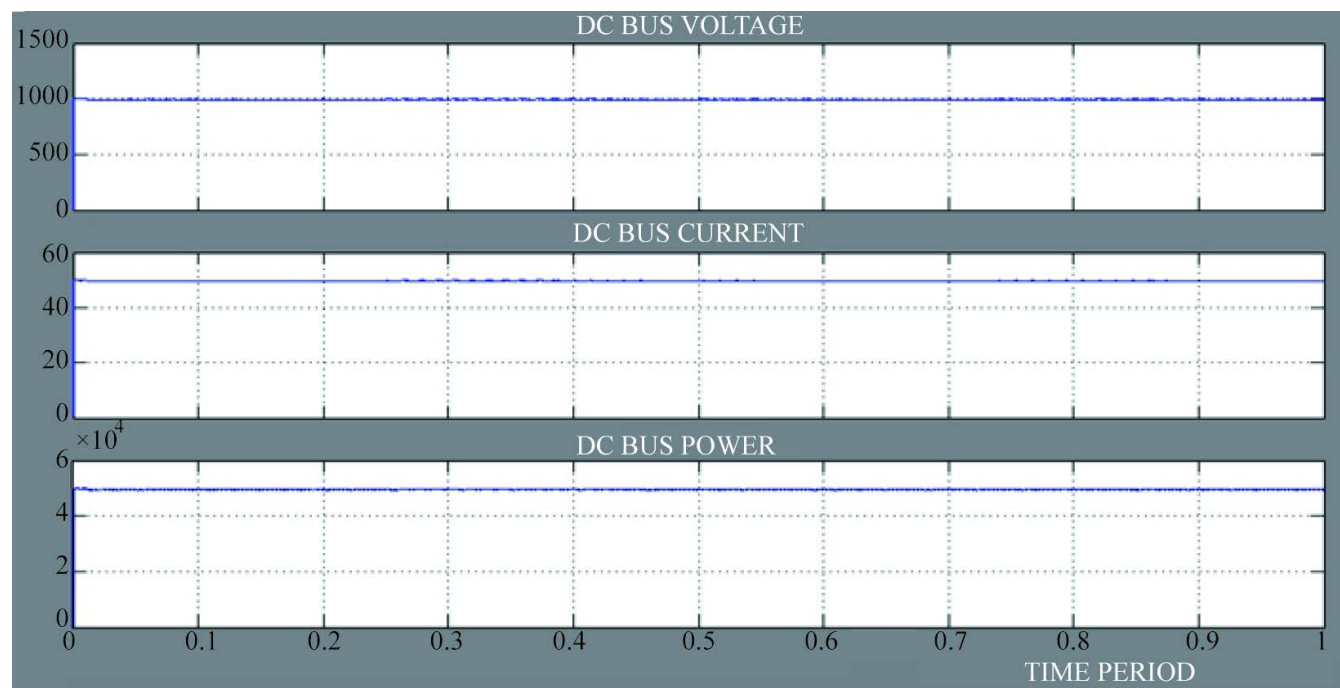

Figure 9. DC bus voltage, current and power.

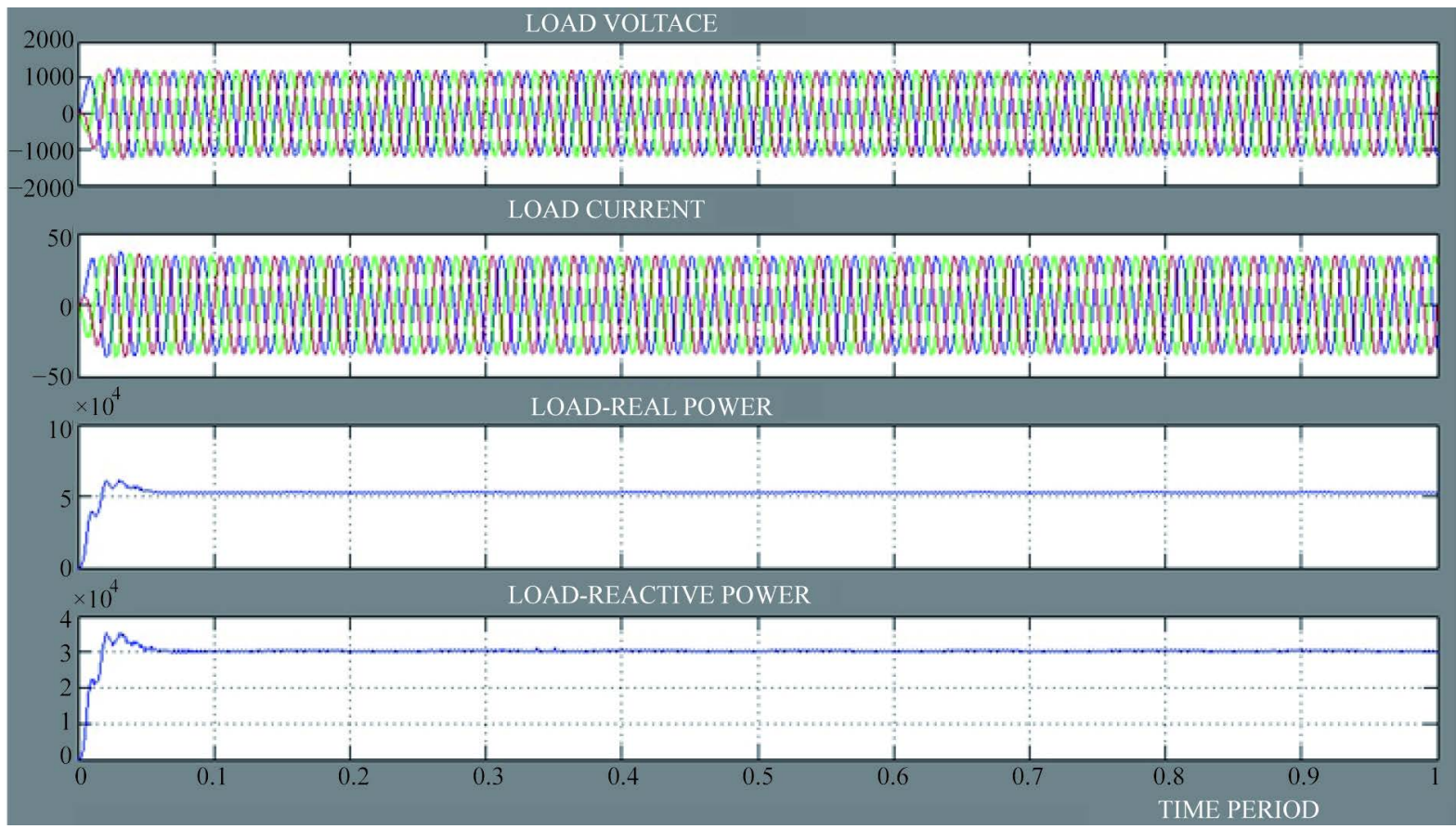

Figure 10. Load side voltage, current, real power and reactive power. 
Table 1. Input parameters.

\begin{tabular}{ccc}
\hline & & Input parameters \\
Source & Rating & Lifetime (Years) \\
\cline { 2 - 3 } PV & $25 \mathrm{KW}$ & 20 \\
Battery & $200 \mathrm{AH}$ & 3 \\
Wind & $25 \mathrm{KW}$ & 15 \\
\hline
\end{tabular}

Table 2. Simulation results.

\begin{tabular}{cccc}
\hline \multirow{2}{*}{ Algorithm } & \multicolumn{3}{c}{ Simulation Results } \\
\cline { 2 - 4 } & Total Cost & Excess Energy & THD \\
\hline GA/PSO & 4.7570 & 1.1270 & 0.54 \\
\hline
\end{tabular}

Using historical data, Wind, PV generation, battery and loads are stochastically modeled. Genetic algorithm (GA) and Particle Swarm Optimization (PSO) algorithms are proposed to minimize the cost and THD and to increase the energy efficiency. Wind cost is obtained as 3.0734 and PV cost as 14.2063. Simulation results are shown in Table 2. The lower value of excess energy obtained results in better efficiency. The fitness function, which is the installation cost for the system is thus achieved satisfying Equation (24). Installation cost spent is taken back over a period of time with no maintenance cost. This system gives improved result for the reason that if some liability happens either in PV panel or in wind turbines, storage system takes charge in supplying incessant power supply to meet the load demand.

\section{References}

[1] Mukherjee, N. and Strickland, D. (2015) Control of Second-Life Hybrid Battery Energy Storage System Based on Modular Boost-Multilevel Buck Converter. IEEE Transactions on Industrial Electronics, 62, 1034-1046. http://dx.doi.org/10.1109/TIE.2014.2341598

[2] Mendis, N., Muttaqi, K.M. and Perera, S. (2014) Management of Battery-Super capacitor Hybrid Energy Storage and Synchronous Condenser for Isolated Operation of PMSG Based Variable-Speed Wind Turbine Generating Systems. IEEE Transactions on Smart Grid, 5, 944-953. http://dx.doi.org/10.1109/TSG.2013.2287874

[3] Arai, J., Iba, K., Funabashi, T., Nakanishi, Y., Koyanagi, K. and Yokoyama, R. (2008) Power Electronics and Its Application to Renewable Energy in Japan. IEEE Circuits and Systems Magazine, 8, 52-66. http://dx.doi.org/10.1109/MCAS.2008.928420

[4] Kang, X., Chia, Y.-K., Ho, C.K. and Sun, S. (2014) Cost Minimization for Fading Channels with Energy Harvesting and Conventional Energy. IEEE Transactions on Wireless Communications, 13, 4586-4598.

[5] Nguyen, C.-L., Lee, H.-H. and Chun, T.-W. (2015) Cost-Optimized Battery Capacity and Short-Term Power Dispatch Control for Wind Farm. IEEE Transactions on Industry Applications, 51, 595-606. http://dx.doi.org/10.1109/TIA.2014.2330073

[6] Kellogg, W.D., Nehrir, M.H., Venkataramanan, G. and Gerez, V. (1998) Generation Unit Sizing and Cost Analysis for Stand-Alone wind, photovoltaic, and hybrid wind PV systems. IEEE Transactions on Energy Conversion, 13, 70-75. http://dx.doi.org/10.1109/60.658206

[7] Jaganmohan Reddy, Y., Pavan Kumar, Y.V., Padma Raju, K. and Ramesh, A. (2012) Retrofitted Hybrid Power System Design with Renewable Energy Sources for Buildings. IEEE Transactions on Smart Grid, 3, 2174-2187. http://dx.doi.org/10.1109/TSG.2012.2217512

[8] Lu, M.-S., Chang, C.-L., Lee, W.-J. and Wang, L. (2009) Combining the Wind Power Generation System with Energy Storage Equipment. IEEE Transactions on Industry Applications, 45, 2109- 2115. http://dx.doi.org/10.1109/TIA.2009.2031937

[9] Colson, C.M., Hashem Nehrir, M., Sharma, R.K. and Asghari, B. (2014) Improving Sustainability of Hybrid Energy Systems Part II: Managing Multiple Objectives with a Multi agent System. IEEE Transactions on Sustainable Energy, 5, 46-54. http://dx.doi.org/10.1109/TSTE.2013.2269319

[10] Somayajula, D. and Crow, M.L. (2014) An Ultra Capacitor Integrated Power Conditioner for Intermittency Smoothing and Improving Power Quality of Distribution Grid. IEEE Transactions on Sustainable Energy, 5, 1145-1155. 
http://dx.doi.org/10.1109/TSTE.2014.2334622

[11] Xu, L., Ruan, X.B., Mao, C.X., Zhang, B.H. and Luo, Y. (2013) An Improved Optimal Sizing Method for Wind-SolarBattery Hybrid Power System. IEEE Transactions on Sustainable Energy, 4, 774-785.

[12] Wais, R.-J. and Wang, W.-H. (2008) Grid-Connected Photovoltaic Generation System. IEEE Transactions on Circuits and Systems -I: Regular Papers, 55, 953-964. http://dx.doi.org/10.1109/TCSI.2008.919744

[13] Wai, R.-J., Wang, W.-H. and Lin, C.-Y. (2008) High-Performance Stand-Alone Photovoltaic Generation System. IEEE Transactions on Industrial Electronics, 55, 240-250. http://dx.doi.org/10.1109/TIE.2007.896049

[14] Alsayed, M., Cacciato, M., Scarcella, G. and Scelba, G. (2013) Multicriteria Optimal Sizing of Photovoltaic-Wind Turbine Grid Connected Systems. IEEE Transactions on Energy Conversion, 28, 370-379. http://dx.doi.org/10.1109/TEC.2013.2245669

[15] Arabali, A., Ghofrani, M., Etezadi-Amoli, M. and Fadali, M.S. (2014) Stochastic Performance Assessment and Sizing for a Hybrid Power System of Solar/Wind/Energy Storage. IEEE Transactions on Sustainable Energy, 5, 363-371.

[16] Arriaga, M., Cañizares, C.A. and Kazerani, M. (2014) Northern Lights. IEEE Transaction on Power and Energy Magazine, 12, 50-59. http://dx.doi.org/10.1109/MPE.2014.2317963

[17] Pourmousavi, S.A., Nehrir, M.H., Colson, C.M. and Wang, C.S. (2010) Real-Time Energy Management of a StandAlone Hybrid Wind-Micro turbine Energy System Using Particle Swarm Optimization. IEEE Transactions on Sustainable Energy, 1, 193-201.

[18] Shadmand, M.B. and Balog, R.S. (2014) Multi-Objective Optimization and Design of Photovoltaic-Wind Hybrid System for Community Smart DC Micro grid. IEEE Transactions on Smart Grid, 5, 2635-2643. http://dx.doi.org/10.1109/TSG.2014.2315043

[19] Deb, K., Pratap, A., Agarwal, S. and Meyarivan, T. (2002) A Fast and Elitist Multiobjective Genetic Algorithm: NSGA-II. IEEE Transactions on Evolutionary Computation, 6, 182-197. http://dx.doi.org/10.1109/4235.996017

[20] Arabali, A., Ghofrani, M., Etezadi-Amoli, M., Fadali, M.S. and Baghzouz, Y. (2013) Genetic-Algorithm-Based Optimization Approach for Energy Management. IEEE Transactions on Power Delivery, 28, 162-170.

\section{Submit or recommend next manuscript to SCIRP and we will provide best service for you:}

Accepting pre-submission inquiries through Email, Facebook, Linkedin, Twitter, etc A wide selection of journals (inclusive of 9 subjects, more than 200 journals)

Providing a 24-hour high-quality service

User-friendly online submission system

Fair and swift peer-review system

Efficient typesetting and proofreading procedure

Display of the result of downloads and visits, as well as the number of cited articles

Maximum dissemination of your research work

Submit your manuscript at: http://papersubmission.scirp.org/ 